\title{
Surgical Exposure of Impacted Upper Right central Incisor and Its Proper Alignment in the Dental Arch
}

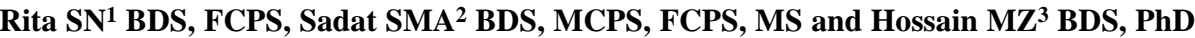

\begin{abstract}
Reported case is of a 9-year-old-girl with unerupted malposed upper right central incisor, which was treated by sequential surgical exposure and fixed orthodontic treatment. The tooth was aligned in the dental arch with accepted aesthetic and functional satisfaction of the patient.
\end{abstract}

Key Words: Impacted tooth, surgical exposure, fixed orthodontics (Ban J Orthod \& Dentofac Orthop, April 2011; Vol1, No. 2, 16-17)

\section{INTRODUCTION}

Permanent tooth eruption failure can create orthodontic problem. A localized problem is typically created by displacement of a permanent tooth from its normal eruption path so that the tooth becomes impacted and maxillary canines are mostly affected ${ }^{1}$. Impaction of Upper Central Incisor is not a common problem for the orthodontists. This type of case can be managed by both surgical and orthodontic approaches 2,3 . The patient presented in this case report, exhibited a challenging and difficult impaction of right upper central incisor, the correction of which required orthodontic traction of impacted tooth after being surgically exposed. The patient was treated by surgical exposure of upper right central incisor and immediately standard edgewise fixed appliance was fitted and then orthodontically brought into the dental arch with proper alignment.

\section{HISTORY AND CLINICAL EXAMINATION}

A 9 year-old girl came to our department with the complain of failure of eruption of a tooth in her upper jaw as her chief complaint. Patient's mother was aware of this problem and wanted proper treatment even with the aid of surgery. The patient had a straight profile with competent lip and good facial symmetry. An angle class-1 malocclusion with impacted upper right central incisor was noted (Fig 1, 2, 3). Clinical assessment of mandibular closure from rest position to habitual occlusion showed no mandibular displacement. No signs or symptoms of TMJ pathology were noted. Panoramic radiography revealed the presence of all permanent teeth with impacted (labio-version) upper right central incisor with deciduous canine and molar teeth (Fig 7).

\section{TREATMENT OBJECTIVES}

Study of the model, clinical features and panoramic radiography revealed the need of the following treatment objectives-

1. Surgical exposure of upper right central incisor

2. Proper alignment of teeth for aesthetic purposes and prevention of further development of any pathological lesion.

\section{TREATMENT PLAN AND PROGRESS}

The patient was treated in three phases: (1) surgical exposure, (2) attachment to the tooth and (3) orthodontic mechanics to bring the tooth into the arch. First the tooth was exposed surgically by

Pre-Treatment Photographs

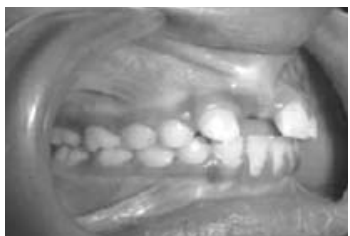

Fig 1: Rt. Lateral View

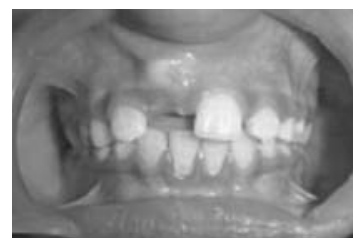

Fig 2: Front view

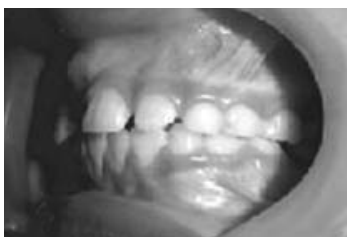

Fig 3: Lt. Lateral View

Photographs during Treatment

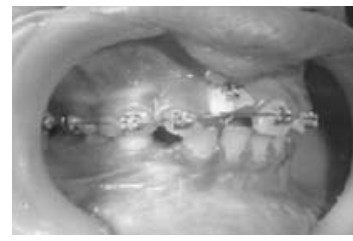

Fig 4: Rt. Lateral View

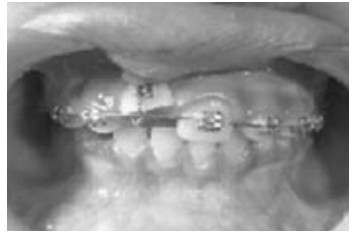

Fig 5: Front view

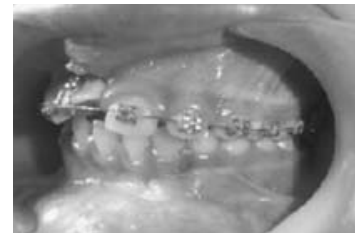

Fig 6: Lt. Lateral View

\footnotetext{
${ }^{1}$ Assit. Prof. \& Head, Department of Orthodontics, Sapporo Dental College. ${ }^{2}$ Lecturer, Department of Oral and Maxillofacial Surgery, Dhaka Dental College. ${ }^{3}$ Professor \& Head, Department of Orthodontics \& Dentofacial Orthopedics, Dhaka Dental College.
} 


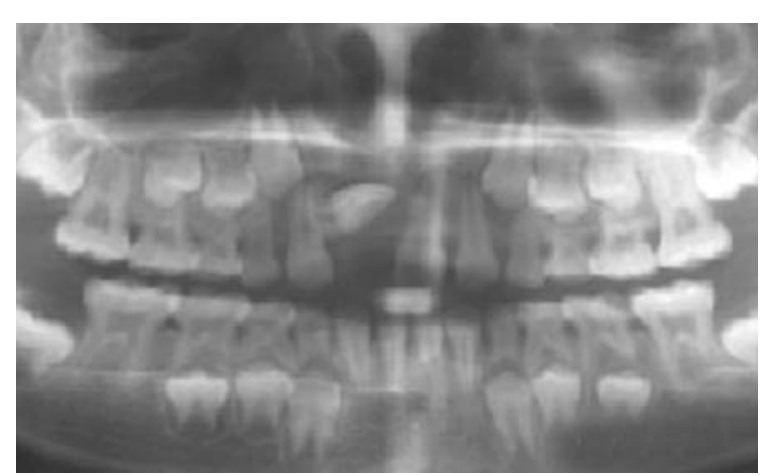

Fig 7:Pre-treatment Panoramic Radiograph

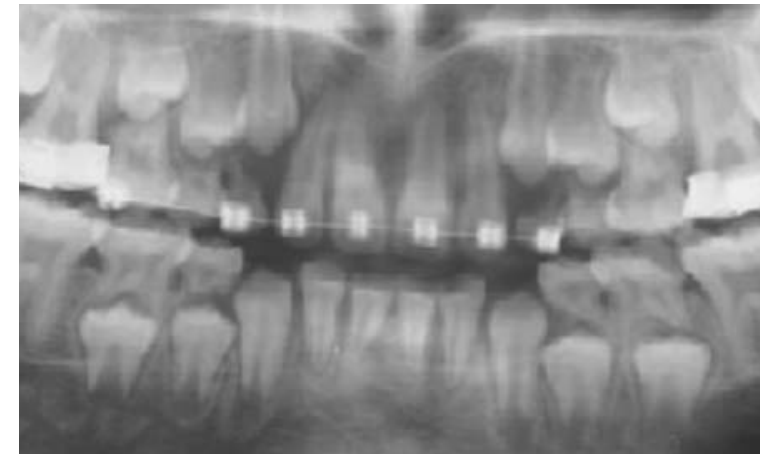

Fig 8: Post-treatment Panoramic Radiograph

Intra oral photographs after treatment

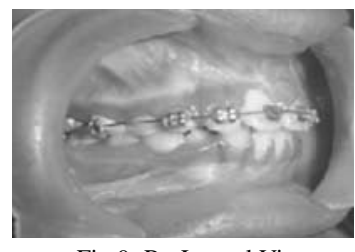

Fig 9: Rt. Lateral View

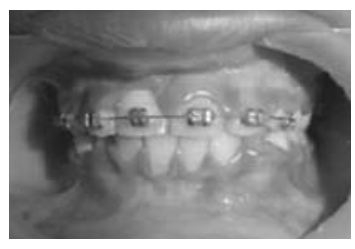

Fig 10: Front view

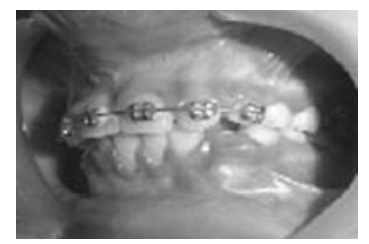

Fig 11: Lt. Lateral View reflecting the flap of the crest of the alveolus and sutured so that attached gingiva has been transferred to the region where the crown is exposed and waited for two to three weeks for spontaneous eruption ${ }^{4}$. The tooth projected towards the upper lip. Then palatal button was bonded on the palatal surface of the tooth. The standard edgewise-fixed appliance was set in the upper arch and traction from the central incisor was given for downward movement of tooth. After the movement, bracket was set on the labial surface of tooth and treatment completed (Fig 4,5,6).

\section{RESULTS}

One year after the initial treatment, the patient was consulted again with pre-treatment and post-treatment records. A class-1 incisor relation was achieved with optimal over-bite and over-jet relationship (Fig 9, 10, 11). The post treatment panoramic radiography revealed a complete eruption of upper right central incisor. The roots of the tooth were fairly parallel, supporting tissues appeared healthy clinically and radiologically (Fig 10, 8).

\section{DISCUSSION}

Proper treatment of this case showed improvement of aesthetics and prevention of development of any pathological condition. The relationship of both dentitions was improved. However, there was a risk of damage to tooth during surgical exposure as the tooth was severely impacted. Alternate option is surgical transplantation. External root resorption often ensues after transplantation and is the major failure ${ }^{5,6,7}$. But use of fixed appliance with controlled movement of tooth helped the patient to a more improved functional dental and aesthetic relationship. To enhance the long-term stability of the results, the fixed appliance should be kept in place up to eruption of permanent canine. Timely and proper orthodontic treatment with the cooperation of the patient and patient's parents are instrumental in the success of treatment ${ }^{6}$.

\section{REFERENCES}

1. Dachi SF, Howel FV. A survey of 3874 routine full mouth radiographs: A study of impacted teeth. Oral Surg Oral Med Oral Pathol 1961; 14(10):1165-1169.

2. Becher A. The orthodontic treatment of impacted teeth. St. Louis, 1998, Mosby.

3. Bishara SE: Clinical management of impacted maxillary canines, Semin orthod 1998;4(2):87-98.

4. Vermette ME, Kokich VG, Kennedy DB. Uncovering labially impacted teeth-apically positioned flap and closed eruption technique. Angle orthod 1995;65:23-32.

5. Moss JP. The unerupted canine. Dent Prac 1972; 22:241-248.

6. Roy S. Am J Orthod Dentofacial Orthop 1998; 114:189-94.

7. Lewis B, Durning P, McLaughlin W, Nicholson PT. Canine transposition following trauma and loss of a central incisor: treatment options. Journal of Orthodontics 2005; 32(1):11-19.

\section{Correspondence}

\section{Dr. Sufia Nasrin Rita BDS, FCPS}

Assit. Professor \& Head.

Department of Orthodontics, Sapporo Dental College.

E-mail : rita_sadat@yahoo.com, Cell : 01711985427 